\title{
Investigations of the thermal stability of the submicrocrystalline titanium
}

\author{
S. S. Manokhin* and M.B. Ivanov \\ Belgorod National Research University \\ Belgorod, Russia \\ manohin@bsu.edu.ru
}

\begin{abstract}
Methods of transmission including high-resolution electron microscopy were used to examine the kinetics of collective recrystallization in submicrocrystalline titanium Grade-4 and VT1-0. The temperature dependence and values of the activation energy for collective recrystallization have been determined. Problems of practical implementation of submicrocrystalline unalloyed titanium in medicine are discussed.
\end{abstract}

Keywords—submicrocrystalline titanium; recrystallization; severe plastic deformation; high resolution transmission electron microscopy; spectroscopy of characteristic electron energy loss; titanium carbide; semi-coherent inclusions

\section{INTRODUCTION}

Production of new constructional and functional materials with improved properties relies on the results of basic research of the mechanism of formation of their structure and on the nature of the physicochemical processes that occur in materials of this type in actual conditions of their production and use. In particular, the lengthening of the grain boundaries due to a decrease in sizes of grains and phases at transition from conventional polycrystalline condition to a submicrocrystalline (SMC) and, especially, to a nanocrystalline (NC) condition and nanostructured (NS) materials results in substantial changes in a heat effect and charge transfer, plastic deformation and fracture, structure degradation and other processes $[1,2]$. In the literature, the terms submicrocrystalline and nanocrystalline generally refer to materials whose grain size ranges from 0.1 to $1 \mu \mathrm{m}$ and less than $0.1 \mu \mathrm{m}$, respectively. Materials (including composites) which are produced, as a rule, by using an external action (e.g., severe plastic deformation (SPD)) or by other methods, are called nanostructured. The structural elements of materials of this type have at least one dimension less than 0.1 $\mu \mathrm{m}$. For the metal materials processed by SPD methods the structural dispersion is often characterized by the size of grainsubgrain structure elements measured experimentally (e.g., by using transmission or scanning electron microscopy), which generally do not coincide with the spacing between high-angle boundaries, i.e. with the grain size of the polycrystal.

One of the perspective materials for fabrication of various implants for stomatology, traumatic surgery, and podiatric medicine is nanostructural and submicrocrystalline pure titanium Grade 2, Grade 4, and VT1-0) [3, 4]. The unique feature of NS unalloyed titanium, compared to other technically pure metals in the nanostructural state (with the melting joint close to titanium), is a high thermal stability of a nanostructure [5]. That makes it possible to conduct annealing

The work has been performed under Russian Science Foundation (contract No 15-12-30010) and State contract No. 3.1492.2014/K to reduce the macroscopic stresses in rods and profiles of NS titanium, providing stability of the metal structure to a climatic action and high properties of articles for a long time of functioning at the temperature of the human body. However, the question about the causes of thermal stability of technically pure titanium in the nanostructural state is opened. It is assumed that the presence of lightly soluble impurities (carbon) is a reason for high thermal stability $[3,6]$. Precipitates that impede migration of grain boundaries in titanium are carbides, which can form in hexagonal close packed (hcp) titanium due to low solubility of carbon at low temperatures. In fact, in the works of the authors [7], it was found that fine partially coherent particles exist in technically pure titanium (VT1-0) after different heat treatments. Other authors relate the process of stabilizing of grain boundaries in NS titanium to grain boundary segregations of carbon [4].

In the present paper, the basic attention is given to the discussion of the results of investigations of the features and mechanisms of diffusion-controlled growth of grains during recrystallization of SMC and $\mathrm{NC}$ titanium, which finds more and wider application in traumatology, orthopedy, and stomatology. Original results obtained by the authors and a review of previous studies are presented. In this paper the discussion is focused on the features and mechanisms of the diffusion-controlled processes developing at intercrystalline interfaces in metal systems with SMC structure in the NS state, and also on the contribution of the mentioned processes to the structure formation and properties.

\section{Test MAterial AND INVESTIGATION PROCEDURE}

The studies were performed using VT1-0 and Grade-4 pure titanium as an example. Chemical composition VT1-0 in wt \% is as follows: $\mathrm{Al}-0.010 ; \mathrm{C}-0.004 ; \mathrm{N}-0.003 ; \mathrm{Fe}-0.120$; $\mathrm{Si}-0.002 ; \mathrm{H} 2-0.0008 ; \mathrm{O}-0.143 ; \mathrm{Ti}$ is the base. Chemical composition Grade- 4 in wt \% is as follows: $\mathrm{Fe}-0,39$, $\mathrm{O}-$ 0,$34 ; \mathrm{C}-0,006 ; \mathrm{N}-0,004 ; \mathrm{H} 2-0,003$; $\mathrm{Ti}$ is the base. In the previously conducted studies the authors developed regimes of thermomechanical treatment of VT1-0 and Grade-4 alloy with usage of longitudinal and cross screw rolling, which makes it possible to obtain rods of nanostructural titanium $4-10 \mathrm{~mm}$ in diameter [8, 9]. In this work, rods $6 \mathrm{~mm}$ in diameter were subjected to final annealing at the temperature of $623 \mathrm{~K}$ for $3 \mathrm{~h}$ for reduction of internal stresses.

The growth of grains was studied for the temperature range 483-743 K. Structural examinations were performed for the longitudinal section to the direction of rolling with the use of a 
Tecnai G2 F20 S-TWIN transmission electron microscope. The following methods of taking an image were used: light-field and dark-field images were obtained with transmission, including high-resolution, electron microscopy and light-field images were obtained with scanning electronic microscopy accompanied by detection of high-angle scattered electrons. Thin foils for transmission electron microscopy were prepared by mechanical grinding/polishing on a LaboPol-5 installation followed by jet polishing on a TenuPol-5 "Struers" installation with the use of a $20 \% \mathrm{HClO}_{4}+80 \% \mathrm{CH}_{3} \mathrm{CO}_{2} \mathrm{H}$ electrolyte.

Structural studies were performed in a cross section parallel to the rolling direction, i.e., in the plane containing the axis of cylindrical rod. In order to prepare thin foils, jet polishing in $20 \% \mathrm{HClO} 4+80 \% \mathrm{CH} 3 \mathrm{CO} 2 \mathrm{H}$ electrolyte was used (TenuPol5 setup)

Element analysis was performed by the method of energy dispersive $\mathrm{x}$-ray microanalysis with the use of an EDAX attachment to the transmission electron microscope and Genesis Microanalysis Software in the STEM mode and by the method of characteristic electron energy losses spectroscopy (EELS). The EELS spectrum has been obtained at an accelerating voltage of $200 \mathrm{kV}$ in a converging beam (nanoprobe) mode (the beam diameter was $10 \mathrm{~nm}$ ) with the use of a post column sector-type filter (Gatan 860 GIF 2001) allowing $0.7 \mathrm{eV}$ resolution and have been analyzed with the use of the Digital Micrograph v.1.8 software package (background subtraction and deconvolution).

The grain growth activation energy was determined from the temperature dependence of the kinetic parameter

$$
\mathrm{C}=\mathrm{A}_{0} \exp (-\mathrm{Q} / \mathrm{RT})
$$

in Arrhenius-type relation

$$
\mathrm{D}^{2}-\mathrm{D}_{0}^{2}=\mathrm{Ct}
$$

where, $\mathrm{Q}$ is the activation energy for the grain boundary migration, D- grain size, D0 - initial grain size, $\mathrm{t}$ - time; A0 constant, $\mathrm{R}$ - universal gas constant. The linear approximation and the activation energy value were obtained by the method of least squares.

\section{EXPERIMENTAL RESULTS AND DISCUSSION}

The microstructure characteristics and mechanical properties of titanium in the initial NS state are given elsewhere [4]. It should be noted that the material structure contains in the main high-angle grain boundaries whose fracture makes about $76 \%$. In the present work, for investigating the processes of collective recrystallization, the mean size of elements of the grain-subgrain structure was determined. For this purpose histograms of the subgrain size distribution over horizontal and vertical secants where constructed, and then averaging was performed. Thus, not only high-angle, but also low-angle boundaries have been taken into account.
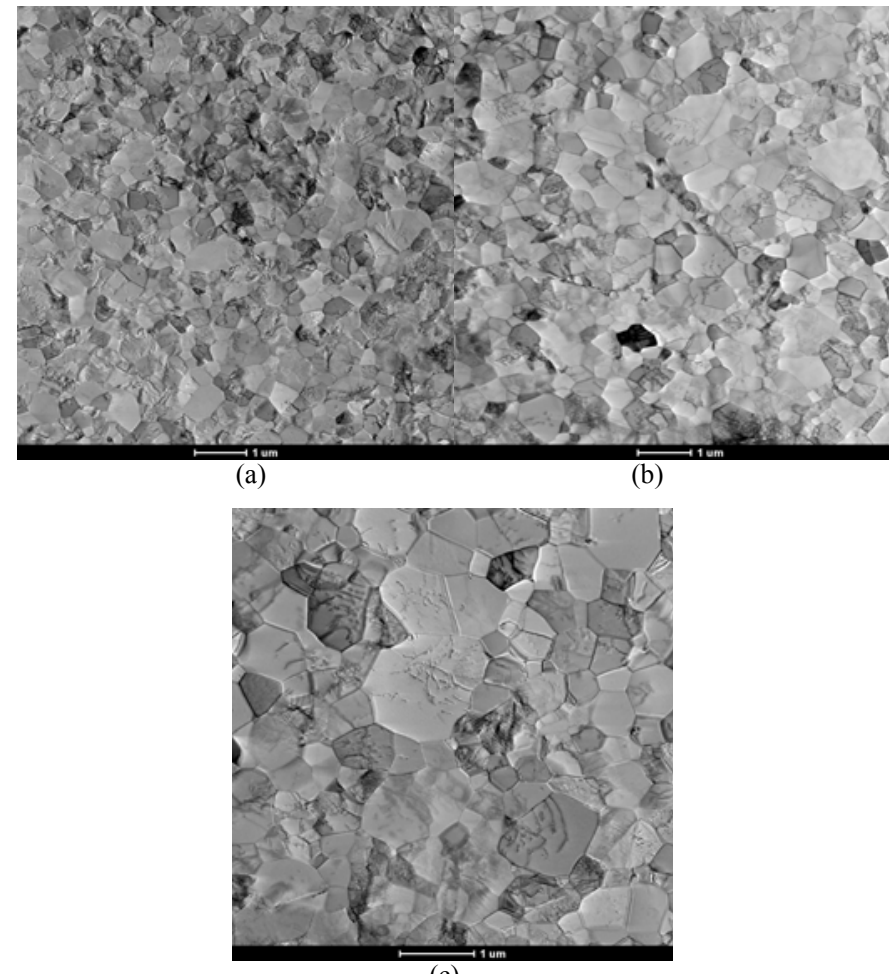

(c)

Fig. 1. Microstructure of titanium Grade- 4 in the initial nanostructured state (a), after $683 \mathrm{~K}, 64 \mathrm{~h}$ (b) and after $763 \mathrm{~K}, 4 \mathrm{~h}$ (c) annealing (submicrocrystalline state). Scanning transmission electron microscopy [10].

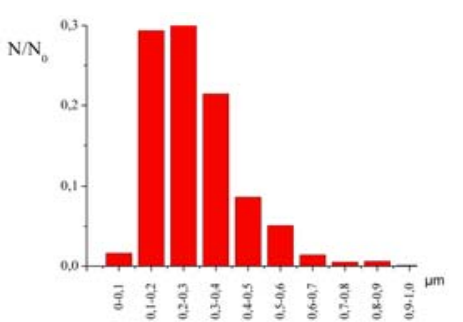

(a)

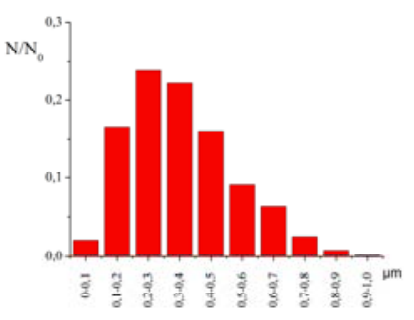

(b)

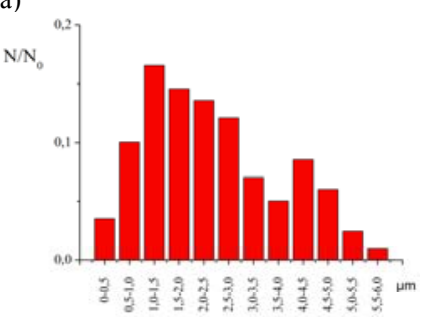

(c)

Fig. 2. Histogram of the subgrain size distribution for titanium Grade-4 in the initial nanostructured state (a) and after $683 \mathrm{~K}$ (b), $64 \mathrm{~K}$ and $763 \mathrm{~K}, 4 \mathrm{~h}$ annealing (c) (submicrocrystalline state) [10].

Fig. 1 gives an image of the microstructure and Fig. 2 a histogram of the subgrain size distribution for titanium VT1-0 in the initial NS state and after annealing at $683 \mathrm{~K}$ [10].

The temperature dependence of the kinetic parameter $\mathrm{C}$ from (1) in the approximation of the exponent $n$ equal to $2,3,6$ and 11 is given in Fig. 3. 
In the quadratic approximation of the grain growth the temperature dependence of $\mathrm{C}$ can be subdivided into three sections which can be conventionally named "lowtemperature", "elevated-temperature", and "high-temperature". (a)

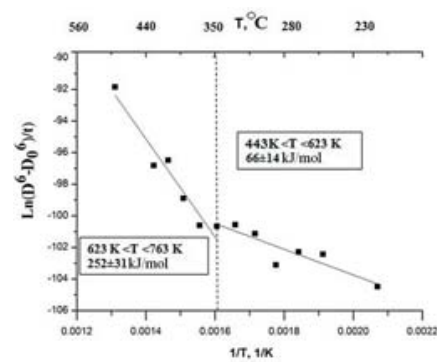

(c)

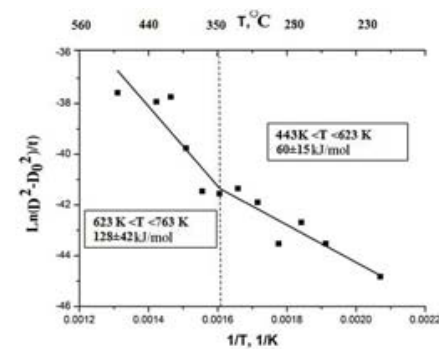

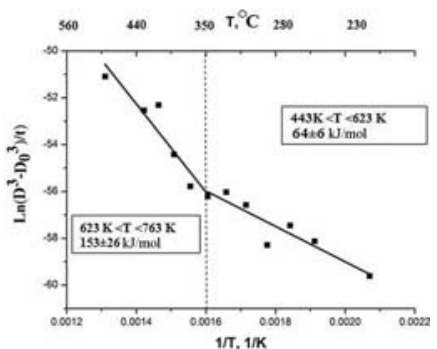

(b)

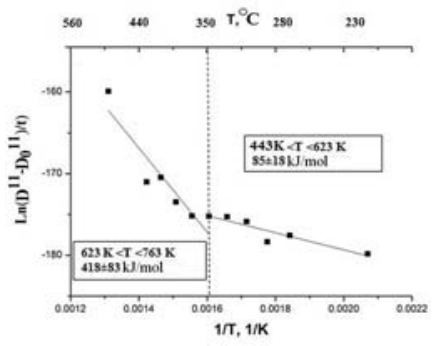

(d)
Fig. 3. Temperature dependence of the rate of grain growth in submicrocrystalline titanium Grade- 4 in the approximation of the exponent $n$ $=2(a), 3(\mathrm{~b}), 6(\mathrm{c})$ and $11(\mathrm{~d})[10]$

For high annealing temperatures (above $743 \mathrm{~K}$ ), abnormal grain growth is observed and described by a bimodal grain size distribution (see Fig. 2c). The occurrence of the second maximum is related to the observed growth of individual coarse grains (see Fig. 1c). It is well known that one of the most spread reason for abnormal grain growth is the nonuniform distribution of the second phase particles that hinder migration of grain boundaries. However, in the case under consideration, another reason for this can be the presence of low-angle subgrain boundaries which substantially differ in mobility from high-angle boundaries. As a result, the grain growth kinetics is different: in this case, it should not obey a quadratic dependence of the grain size on time. In addition, the existence of two possible reasons for the abnormal growth of grains (subgrains) can introduce some indeterminacy in a comparison of experimental data with theoretical predictions.

We use in calculations the kinetic relation with the exponent $n$ equal 3, because error of activation energy is minimal. For low temperatures the kinetic dependence with $n=$ 3 and an activation energy of $64 \mathrm{~kJ} / \mathrm{mol}$ shows the best convergence of data. Anyway, irrespective of the choice of $n$, the experimentally determined grain growth activation energy cannot exceed $90 \mathrm{~kJ} / \mathrm{mol}$ at temperatures below $623 \mathrm{~K}$. At elevated temperatures (below $723 \mathrm{~K}$ but above $623 \mathrm{~K}$ ) the grain growth can be considered normal; for this case, the activation energy is determined from experimental data and is equal to $(153 \pm 26) \mathrm{kJ} / \mathrm{mol}$. The low-temperature range of grain growth is characterized by the activation energy $(64 \pm 6) \mathrm{kJ} / \mathrm{mol}$. It should be noted that in experiments on investigation of the grain growth in titanium, another kinetic dependence of the grain size on time was often observed after isothermal annealings (see [11]).

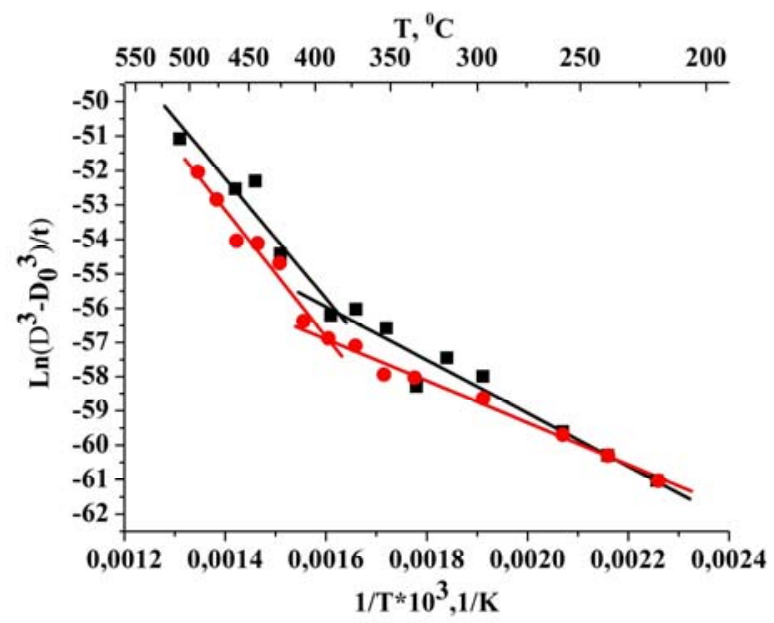

Fig. 4. Temperature dependence of the rate of grain growth in submicrocrystalline titanium Grade- 4 and VT1-0 in the approximation of the exponent $n=3$. Points: circle- VT1-0, square-Grade 4

TABLE I. VALUES OF THE “EFFECTIVE” CREEP ACTIVATION ENERGY QC AND ACTIVATION ENERGIES FOR COLLECTIVE RECRYSTALLIZATION, QREC (ORIGINAL DATA), VOLUMETRIC SELF-DIFFUSION, QV, AND GRAINBOUNDARY SELF-DIFFUSION, QB, FOR TITANIUM

\begin{tabular}{|c|c|c|c|c|c|c|}
\hline \multicolumn{2}{|c|}{$\begin{array}{c}\text { Qc, kJ/mol } \\
{[13]}\end{array}$} & \multirow{2}{*}{$\begin{array}{c}\text { Qv, } \\
\mathrm{kJ} / \mathrm{mol} \\
{[14]}\end{array}$} & \multirow{2}{*}{$\begin{array}{c}\text { Qb, } \\
\mathrm{kJ} / \mathrm{mol} \\
{[12]}\end{array}$} & \multirow{2}{*}{$\begin{array}{c}\text { Qb*, } \\
\text { kJ/mol } \\
{[11]}\end{array}$} & \multicolumn{2}{|c|}{ Qrec, kJ/mol } \\
\hline $\begin{array}{c}S M C \\
T=523- \\
623 K\end{array}$ & $C G$ & & & & $\begin{array}{c}S M C \\
T< \\
623 K \\
\end{array}$ & $\begin{array}{c}S M C \\
T> \\
623 \mathrm{~K} \\
\end{array}$ \\
\hline 128 & 252 & 303 & 187 & 70 & $64 \pm 6$ & $\begin{array}{l}153 \pm \\
26\end{array}$ \\
\hline
\end{tabular}

Fig. 4 shows a comparison of the Arrhenius dependence of the rate of grain growth in the submicrocrystalline titanium Grade 4 (obtained in this study) and BT1-0 (obtained by the authors in [12] on the approximation of the value of the exponent $n=3$. It may be noted that there is a correlation between the temperature dependence of alloys VT1-0 and Grade 4. The break in the curves is observed in the same temperature range. The values of the activation energy for the recrystallization temperatures below $623 \mathrm{~K}$ is $64 \pm 6 \mathrm{~kJ} / \mathrm{mol}$ and $51 \pm 2 \mathrm{~kJ} / \mathrm{mol}$ for the titanium mark Grade4 and VT1-0 [11], respectively.

A few larger value of the activation energy for recrystallization Grade 4 may be explained with the influence of inclusion of impurities and segregation at grain boundaries, and higher concentration of carbon in the alloy compared to titanium VT1-0. Above the temperature $623 \mathrm{~K}$ activation energy recrystallization is almost identical (within experimental error) and constitute values $153 \pm 26 \mathrm{~kJ} / \mathrm{mol}$ and $153 \pm 13 \mathrm{~kJ} / \mathrm{mol}$ for Grade4 and VT1-0 [11] respectively. 
It is well known that the kink in the temperature curve of recrystallization rate toward higher activation energies at higher temperatures is accounted for the conventional activation of the migration of grain boundaries due to their breakaway from inclusions or segregates. Analysis of the data of Table I shows that at low temperatures the value of activation energy for collective recrystallization of NS titanium is close to the activation energy for grain-boundary selfdiffusion (measured for the NS state [11]). The increase of the annealing temperature to $623 \mathrm{~K}$ and over results perhaps in the breakaway of grain boundaries from hinder particles or segregates, and this effectively increases the process activation energy and causes abnormal growth of individual grains. The inclusions that hinder the motion of boundaries can be carbides, which should be present in the material in view of the low solubility of carbon in fcp titanium at low temperatures.

Actually, the existence of dispersed partially coherent carbides has been revealed in technically pure titanium (VT10 ) after various thermal treatments [7]. Fine-grained titanium carbides of lamellar morphology were also observed in our experiments on studying grain growth. Thus, after annealing of NS titanium at $683 \mathrm{~K}$ for $8 \mathrm{~h}$, the grain bulk was filled with partially coherent inclusions (Fig. 5a). The particle material, as mentioned previously [7], were identified as carbide with an fcc sublattice of titanium atoms (Fig. 5b).
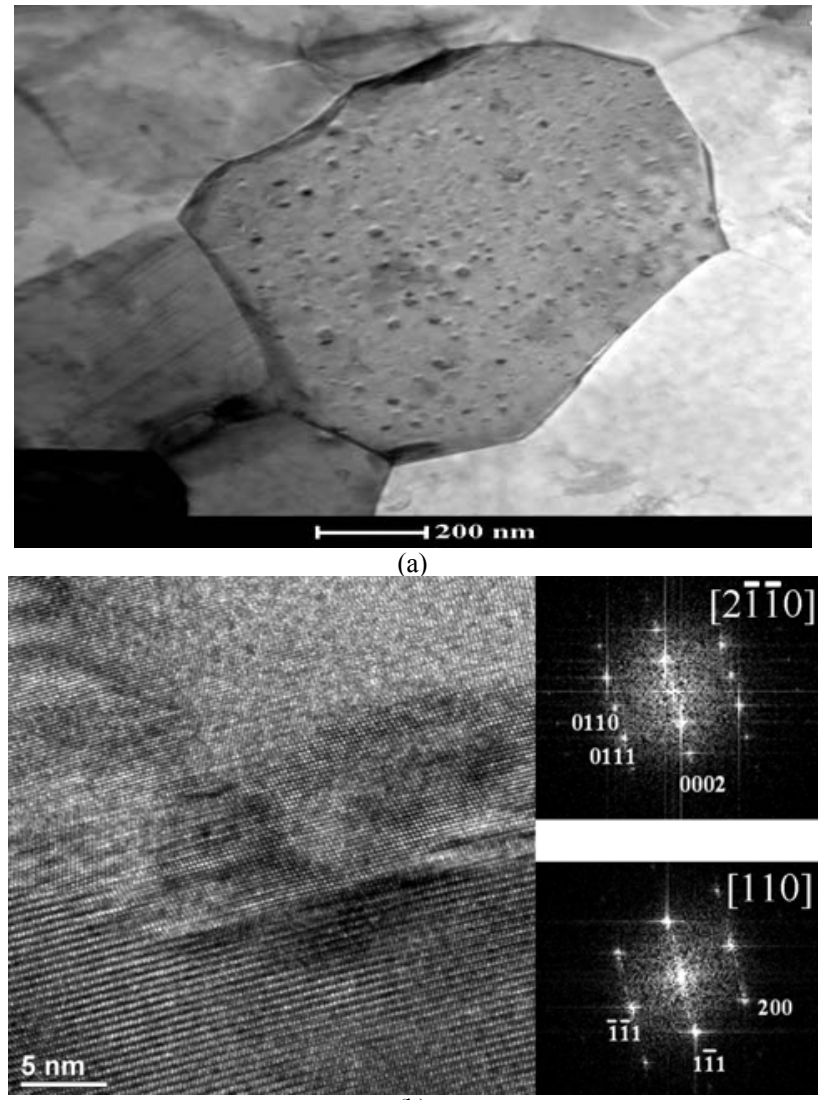

(b)

Fig. 5. Image of titanium carbide particles in NS titanium after annealing at $683 \mathrm{~K}$ : particles in a grain (scanning TEM) $(a)$ and a single particle $(b)$ : the axis of the fcp matrix zone is [ [ $\left.\begin{array}{lll}2 & 1 & 10\end{array}\right]$ and the axis of the fcc particle is [011] (high-resolution TEM with Fourier transformation of the image elements (top: from the matrix, bottom: from the particle) [7].
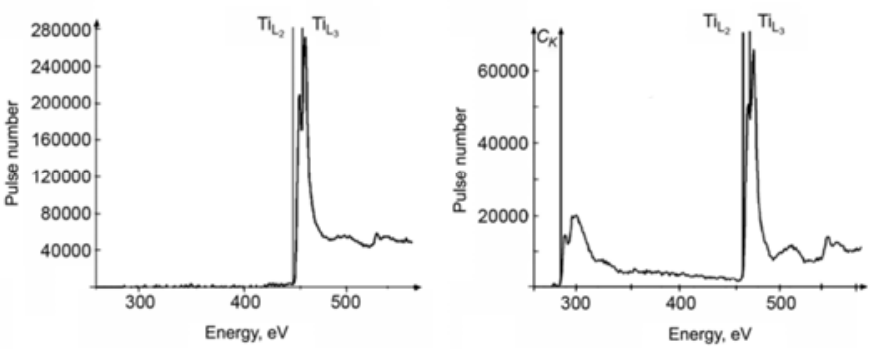

Fig. 6. Spectra of characteristic electron energy losses for the $\alpha$-phase (a) and for the titanium carbide particle presented in Fig. 5 (b) [7].

The EELS spectroscopy data for the inclusions suggest that they are particles of titanium carbides. This is evidenced by the intense absorption peaks in the $K$-line of carbon (Fig. 6) that are not inherent in the titanium. The particles do not contain other elements except carbon and titanium (at least in contents exceeding a few percent's corresponding to the limit of detection by EELS spectroscopy). Other authors [6] related to the stabilization of grain boundaries in NS titanium to grainboundary segregation of carbon. The formation of carbon segregates was just detected in the material subject to annealing at $623 \mathrm{~K}$. Thus, at temperatures over $623 \mathrm{~K}$, grain boundaries can break away from carbon segregates and carbides can form in a grain bulk (see Fig. 5).

According to the available experimental data $[15,16]$, the activation energy for bulk diffusion of carbon in fcp titanium ranges from 128 to $188 \mathrm{~kJ} / \mathrm{mol}$. Unfortunately, data on the grain-boundary diffusion of carbon in titanium are not available (most likely, the activation energy for the grainboundary diffusion of carbon in titanium should be lower than that for bulk diffusion). Thus, the temperature dependence of grain growth in NS titanium can be controlled by both grainboundary self-diffusion and grain-boundary (bulk) diffusion of carbon, depending on the mechanism of migration and its inhibition: by particles or by segregates.

\section{CONCLUSION}

It has been revieled that the temperature dependence of the collective recrystallization in SMC titanium has two pronounced intervals. For recrystallization VT1-0 and Grade4 at elevated temperatures (below $723 \mathrm{~K}$ but above $623 \mathrm{~K}$ ) the grain growth can be considered normal; for this case, the activation energy is determined from experimental data and is equal to $153 \pm 26 \mathrm{~kJ} / \mathrm{mol}$ and $153 \pm 13 \mathrm{~kJ} / \mathrm{mol}$ respectively. Above the temperature $623 \mathrm{~K}$ activation energy recrystallization is almost identical (within experimental error). The low-temperature range of grain growth is characterized by the activation energy $(64 \pm 6) \mathrm{kJ} / \mathrm{mol}$. A few larger value of the activation energy for recrystallization Grade 4 may be explained with the influence of inclusion of impurities and segregation at grain boundaries, and higher concentration of carbon in the alloy compared to titanium VT1-0. Analysis of the results of experimental studies of the diffusion and diffusion-controlled processes in nanostructured metals produced by using intense plastic deformation has been performed. 


\section{REFERENCES}

[1] Yu.R. Kolobov, R.Z. Valiev, and G.P. Grabovetskaya. Grain Boundary Diffusion and Properties of Nanostructured Materials, Cambridge International Science Publishing, p.250, 2007.

[2] Yu.R. Kolobov, E.N. Kablov, and E.V. Kozlov, et al., Structure and Properties of Intermetallic Materials with Nanophase Hardening., MISIS Publishers, p. 328, 2008.

[3] Yu.R. Kolobov, "Nanotechnologies for the formation of medical implants based on titanium alloys with bioactive coatings," Nanotechnol. Russ., vol. 4, no. 11-12, p. 758, 2008.

[4] M.B. Ivanov, Yu.R. Kolobov, E.V. Golosov, I.N. Kuz'menko, V.P. Veinov, D.A. Nechaenko, and E.S. Kungurtsev, "Mechanical properties of mass produced nanostructured titanium," Nanotechnol. Russ., vol. 6, no. 5-6, p. 370, 2011.

[5] Yu.R. Kolobov, A.G. Lipnitskii, M.B. Ivanov, I.V. Nelasov, and S.S. Manokhin, "Investigations of thethermal stability of the microstructure of titanium produced by intense plastic deformation," Russ. Phys. J., vol. 54, no. 8, p. 918, 2011.

[6] I. Semenova, G. Salimgareeva, G. Da Costa, W. Lefebvre, and R. Valiev, "Enhanced strength and ductility of ultrafine grained Ti processed by severe plastic deformation," Adv. Eng. Mater., vol. 12, no. 8, p. 803, 2010.

[7] M.B. Ivanov, S. S. Manokhin, D. A. Nechaenko, and Yu. R. Kolobov, "Features of the crystal structure of dispersing carbides in alpha titanium," Russ. Phys. J., vol. 54, no. 7, p. 749, 2011.

[8] M.B. Ivanov, A.V. Penkin, Yu.R. Kolobov, E.V. Golosov, D.A. Nechaenko, and S.A. Bozhko, "Hot helical rolling in conical shaped rollers as the method of severe plastic deformation," Deform. Razrushen. Mater., no. 9, p. 13, 2010.

[9] Yu.R. Kolobov, M.B. Ivanov, E.V. Golosov, and A.V. Penkin, Method of Production of a Submicrocrystalline Structure in Unalloyed Titanium, Patent of the Russian Federationt No. 2389568, 2010.

[10] Yu.R. Kolobov, M.B. Ivanov, S.S. Manokhin, and E. Erubaev, "Laws of recrystallization submicrocrystalline titanium," Inorganic Materials (in press), 2016

[11] F. Sun, A. Zuniga, P. Rojas, and E.J. Lavernia, "Thermal Stability and Recrystallization of Nanocrystalline Ti Produced by Cryogenic Milling," Metallurg. Mater. Trans. A, 37, pp. 2069-2078, 2006.

[12] S.S. Manokhin, "Regularities of phase and structural transformations in nondoped titanium VT1-0," Candidate's Dissertation (Belgorod, 2012)

[13] G.P. Grabovetskaya, Yu.R. Kolobov, L.V. Chernova, and N.V. Girsova, "Structure and deformation behavior submicrocrystalline titanium creep," vol. 5, No. 6, pp. 87-94, 2002.

[14] Chr. Herzig, T. Wilger, T. Przeorski, F. Hisker, and S. Divinski, "Titanium tracer diffusion in grain boundaries of a-Ti, a2-Ti3Al, and g$\mathrm{TiAl}$ and in a2/g interphase boundaries," Intermetallics, No. 9, pp. 431442, 2001.

[15] S. Suzuki, T. Sato, A. Kurokawa, and S. Ichimura, "Depth Profiling of Characteristic Thin Surface Layers Formed in Titanium by Mechanical Abrasion and Annealing," J. Surf. Anal., vol. 12, no. 2, pp.166-169, 2005 .

[16] C. Arvieu, J.P. Manaud, and J.M. Quenisset, "Interaction between titanium and carbon at moderate temperatures," J. Alloy. Compd. vol. 368, pp. 116-122, 2004. 